\title{
AERIAL RADIOLOGICAL MEASURING SURVEY OF THE AREA SURROUNDING THE ENRICO FERMI ATOMIC POWER PLANT, MONROE, MICHIGAN SEPTEMBER 1970
}

EG\&G, Inc., Las Vegas, Nevada

This report was prepared as an account of work
sponsored by the United States Government. Neither
the United States nor the United States Atomic Energy
Commission, nor any of their employees, nor any of
their contractors, subcontractors, or their employees,
makes any warranty, express or implied, or assumes any
legal liability or responsibility for the accuracy, com-
pleteness or usefulness of any information, apparat us,
product or process disclosed, or represents that its use
would not infringe privately owned rights.

This report is part of a series on the continuing activities of the Aerial Radiological Measuring System operated for the U.S. Atomic Energy Commission. The ARMS program is managed by the Division of Operational Safety and is a cooperative effort among various offices and divisions of the Commission. 


\section{DISCLAIMER}

This report was prepared as an account of work sponsored by an agency of the United States Government. Neither the United States Government nor any agency Thereof, nor any of their employees, makes any warranty, express or implied, or assumes any legal liability or responsibility for the accuracy, completeness, or usefulness of any information, apparatus, product, or process disclosed, or represents that its use would not infringe privately owned rights. Reference herein to any specific commercial product, process, or service by trade name, trademark, manufacturer, or otherwise does not necessarily constitute or imply its endorsement, recommendation, or favoring by the United States Government or any agency thereof. The views and opinions of authors expressed herein do not necessarily state or reflect those of the United States Government or any agency thereof. 


\section{DISCLAIMER}

Portions of this document may be illegible in electronic image products. Images are produced from the best available original document. 


\section{WORK PERFORMED BY}

Instrumentation Specialist

W. F. Verheyden

\section{Navigator}

M. D. Sevart

\section{$\underline{\text { Pilot }}$}

E. D. Shultz

Scientist/Analyst

P. K. Boyns 


\begin{abstract}
The Aerial Radiological Measuring System (ARMS) was used to survey the Enrico Fiermi Atomic Power Plant and surrounding area during September 1970. The survey measured terrestrial background gamma radiation and included a plume track of the stack release gases.

A high-sensitivity detection system collected gamma-ray spectral and gross-count data. The data were then computer processed into a map of a 277 square mile area showing isoexposure contours three feet above the ground. Results indicated the presence of isotopes normally found in the background radiation throughout the United States. The plume track revealed no radiation above background levels.
\end{abstract}

\title{
ACKNOWLEDGMENTS
}

Special appreciation is given to L. J. Deal (Assistant Director, DOS/Health Protection, USAEC) and to Dr. Charles Pelletier (Chief, Environmental Inspection Branch, Regulatory Operations, USAEC) for their support and encouragement in this program. 


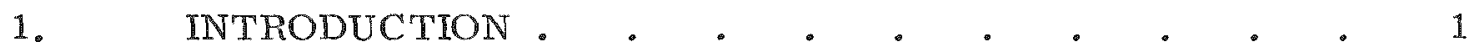

1. 1 Identification of Surveyed Plant and Area . . 1

1.2 ARMS Program . . . . . . . . 1

1.3 ARMS Equipment and Procedures . . . . 1

1. 4 Reduction and Presentation of Data. . . . 4

2. REACTOR AND SITE CHARACTERISTICS . . . . 5

2.1 Reactor Characteristics . . . . . . 5

2.2 Site Area Characteristics . . . . . . 6

3. SURVEY PLAN • • • • • • • • • . 8

3.1 Specification of Flight Lines . . . . . 8

3.2 Coordination with Local Authorities . . . 8

4. RADIOLOGICAL SURVEY • • • • • • . $\quad 9$

4.1 Survey Missions . . . . . . . . 9

4.2 Gross-Count Data . . . . . . . 9

4.3 Spectral Data . . . . . . . . 9

4. 4 Plume Track. . . . . . . . . 11

5. SUMMARY AND CONCLUSIONS $\quad$ • $\quad$ • $\quad$ • 12

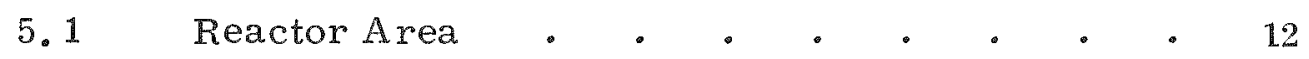

5.2 Plume Track $. \quad \cdot \quad \cdot \quad \cdot \quad \cdot \quad \cdot \quad \cdot \quad . \quad 12$ 


\section{INTRODUCTION}

\section{1 Identification of Surveyed Plant and Area}

The Aerial Radiological Measuring System (ARMS) (Ref. 1) operated by EG\&G, Inc., Las Vegas, Nevada, for the U. S. Atomic Energy Commission was used to survey an extensive area surrounding the Enrico Fermi Atomic Power Plant during September 1970. The Enrico Fermi Plant, operated by the Power Reactor Development Company, is located near Monroe, Michigan. The size of the survey area was 277 square miles.

\subsection{ARMS Program}

The present survey was made as part of a continuing nationwide ARMS program starled in 1958 to monitor radiation levels surrounding facilities producing or utilizing radioactive materials. This survey is the first such performed in the Enrico Fermi area since the station began operation in 1963 .

The detection system on board the aircraft collects gamma-ray gross-count and spectral data on each flight line of the survey. The gamma radiation and aircraft position information are processed by a computer into an isoexposure contour map of the area surveyed.

\subsection{ARMS Equipment and Procedures}

The ARMS aircraft and its on-board radiation detection equipment were used in the survey of the Enrico lermi facility and surrounding area. Since the ARMS equipment and procedures have been discussed in detail elsewhere (Ref. 1), they will only be described briefly here.

The ARMS surveys are flown in a Beechcraft Twin Bonanza at an altitude of 300 to 500 feet above ground level at a ground specd of about 140 knots $(235 \mathrm{ft} / \mathrm{sec}$. The ground position of the aircraft and its altitude above terrain are measured and recorded erery other second by a radar navigation computer system. The position and altitude measurements arc accurate to $\pm 350 \mathrm{ft}$ and $\pm 5 \mathrm{ft}$, respectively.

A typical flight pattern consists of a series of parallel lines oriented in a north-south or east-west direction. The lines are spaced 
at intervals of one nautical mile (6080 fcet) and cover all of the land area within a twelve and one-half nautical mile radius of the facility.

At an altitude of 500 feet, the field of view of the detectors is approximately $1 / 4$ mile wide for a mean gamma energy of naturally occurring isotopes.

The aerial radiation measurements are of two distinct types, made simultaneously: (1) gross gamma count (intensity) measurements and (2) gamma spectral measurements. The detector system consists of an array of fourteen $4 \times 4$ in. NaI ( $T$ l) scintillation crystals, each coupled to its own photomultiplier assembly. The detector system output is directed both to the gross gamma count computing system and to the multichannel spectrum analyzer. The data collecting system is shown in Figure 1.

The gross gamma count system consists of an amplifierdiscriminator-computer unit that counts and records the total number of gamma-rays of energy greater than $50 \mathrm{keV}$ that are detected during a 1 -second time interval. The gross gamma count rate (number of gamma-rays detected per second) is digitally recorded along with aircraft position and altitude every other second. Aircraft position data are supplied by a track navigational computer and doppler radar. Altitude above terrain is measured with a radar altimeter. As a backup and complement to the digital recording of the gross-count data, a record is made on a continuous strip chart of both gross gamma count rate and radar altitude as a function of distance. Typical gross-count rates for natural background are several thousand per second.

Whereas the gross gamma count data specify the intensity of radiation as a function of position, the gamma spectral data are useful in identifying particular radioactive isotopes. A pulse-height analyzer automatically sorts detected gamma-rays according to energy, thereby generating a number per unit-energy versus energy spectrum. Although gamma ravs occur only at well known discrete energies characteristic of the emitting species, air scattering tonds to smear the detected distribution. Nevertheless, the characteristic peaks that permit isotope identification are readily observable. In wide area surveys, the typical acquisition time for a gamma-ray spectrum is several minutes; thus, the spectrum represents the average radiological propertics of a tract several miles in length. However, if an area of interest is indicated by an increase of the gross gamma count data, spectral data acquisition times of only a few seconds are used to isolate the area spatially. If further investigation is warranted, a ground mobile unit with equipment similar to that in the aircraft is available to provide greater spatial and energy resolution. 




FIGURE 1. View of the interior of the Aerial Radiological Measuring System (ARMS) aircraft showing detector package and electronic data collection system. 
In addition to the equipment just described, the ARMS aircraft also carries an air sampling and analysis system, for the measurement of airborne radioactivity.

\subsection{Reduction and Presentation of Data}

The raw data from the gross gamma count and the gamma spectral measurements are permanently recorded on paper tape, which is computer processed and analyzed to characterize the radiological properties of the area surveyed. Using an altitude-dependent conversion factor obtained from prior calibration measurements, the raw gross-count rate is converted to exposure rate $(\mathrm{R} / \mathrm{hr}$ ) at three feet above ground (designated as "terrestrial exposure rate").

The exposure rate conversion factor was obtained from repeated flights 200 to 1000 feet above terrain containing known distributions of natural isotopes. Such conversion factors have proved valid over distributed fission product fields, with a variation of less than $25 \%$. In practice, variations of 2 UR/hr or greater can be reliably observed in repeated flights over the same area. 


\section{REACTOR AND STTE CHARACTFRISTICS}

\section{$2.1 \quad$ Reactor Characteristics}

The Enrico Fermi Reactor is located in Monroe County, 25 miles south of Detroit, near Monroe, Michigan.

The principal nuclear contractor and facility operator is the Power Reactor Development Company.

Table 1 gives the specifications of the reactor facility at the time of the survey. The reactor was coming up to operational power after a long period of shutdown.

TABLE 1. Reactor facility specifications.

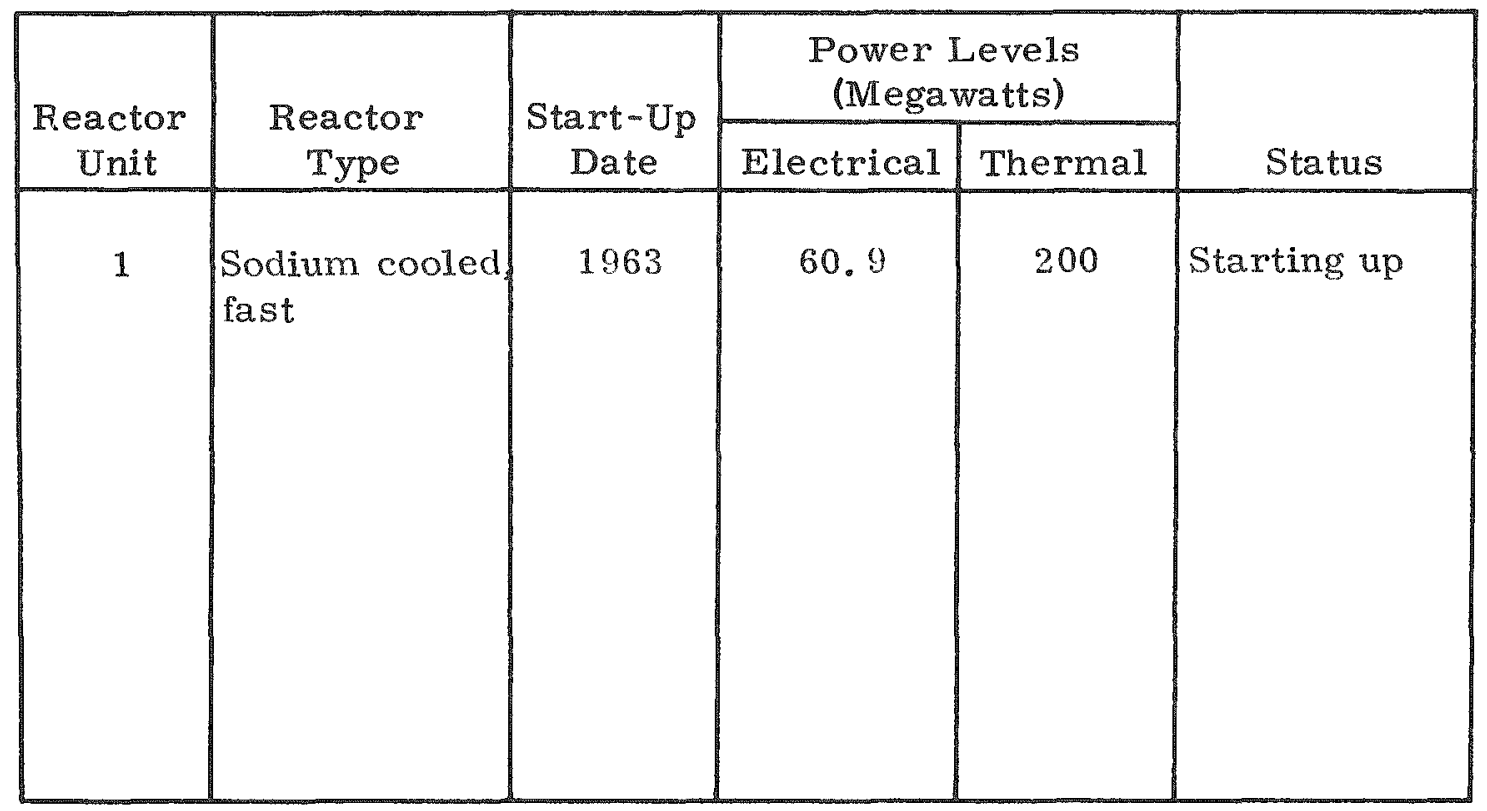




\section{$2.2 \quad$ Site Area Characteristics}

In general the terrain in the survey area is relatively flat farmland interspersed with numerous small streams. The shoreline of Lake Exie forms the eastern boundary of the survey area.

Table 2 gives a breakdown of the population of the survey area in terms of distance and direction from the reactor site $(1970$ census figures - Ref. 2). 
TABLE 2. Population distribution within the Enrico Fermi survey area.

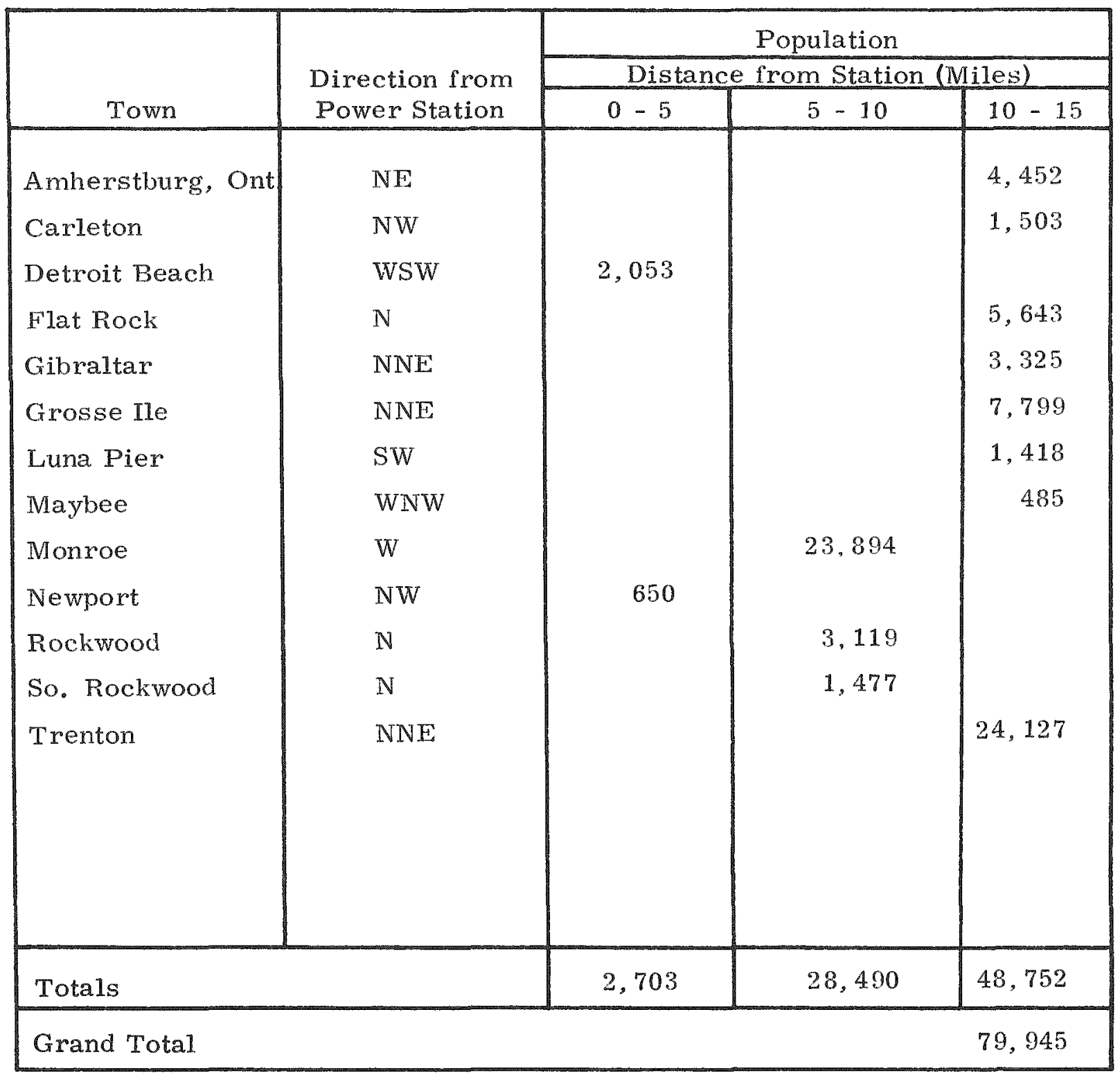




\section{$3.1 \quad$ Specification of Flight Lines}

The flight pattern for the Enrico Fermi survey consisted of 24 flight lines approximately 4 to 16 nautical miles long and spaced one nautical mile apart. The flight lines were oriented in an east-west direction. Radiation data together with aircraft position and meteorological information were collected along each flight line.

\subsection{Coordination with Local Authorities}

ARMS survey missions are conducted under special waiver from the Federal Aviation Administration. The survey plan was discussed with the General Aviation District Office at Detroit, Michigan, and public announcements were published in the local newspapers prior to the survey operation in accordance with the FAA waiver for low-level flights.

Ohio.

The base of operations for the survey mission was Swanton, 


\section{RADIOLOGICAL SURVEY}

\section{1 Survey Missions}

The aerial survey of the Enrico Fermi Reactor area was conducted on 1 September 1970. This survey required a total flying time of 4.4 hours. A plume track mission was also flown on the same date.

Gross-count and spectral data were simultaneously collected at an altitude of 300 fect. One spectrun was accumulated for each f]ight line.

\subsection{Gross-Count Data}

As a first step in the analysis of the gross-count data, the background due to nonterrestrial radiation was subtracted. This background consists of cosmic-rav, aircraft, and airborne radioactivity contributions (Ref. 3). After correction for background, the data were normalized to a standard air mass. The resultant net-count data were then converted to exposure rate in microroentgens per hour ( $\mathrm{F} / \mathrm{hr}$ ) at the 3 -foot level above the ground. The cosmic-ray exposure rate was then added back to the terrestrial exposure rate. Finally, the composite exposure rate data, together with aixcraft position information, were processed into an isoexposure contour map for overlay on U. S. Geological Survey topographic maps of the survey area.

An isoexposure map of the Enrico Fermi Plant a rea is shown in Figure 2 (in pocket, back cover). The data shown on the map include a cosmic radiation contribution of 2 to $4 \mathrm{uR} / \mathrm{hr}$. Spatial resolution of the exposure rate data is determined by the field of view of the detector system, which is about $1 / 4$ mile.

\subsection{Spectral Data}

Spectral data were recorded from about 0.03 to $: 3.0$ Vel. The recording system was calibrated prior to takeoff with an yttrium-88 source, which emits two prominent gamma-ravs of 0.898 and $1.836 \pi \mathrm{T}$. The gain for each crystal in the 14-crystal detector array was set independently.

$\Lambda$ spectrum typical of those taken during the survey is shown in Figure 3. Table 3 lists the prominent gamma-ray energies and associated 


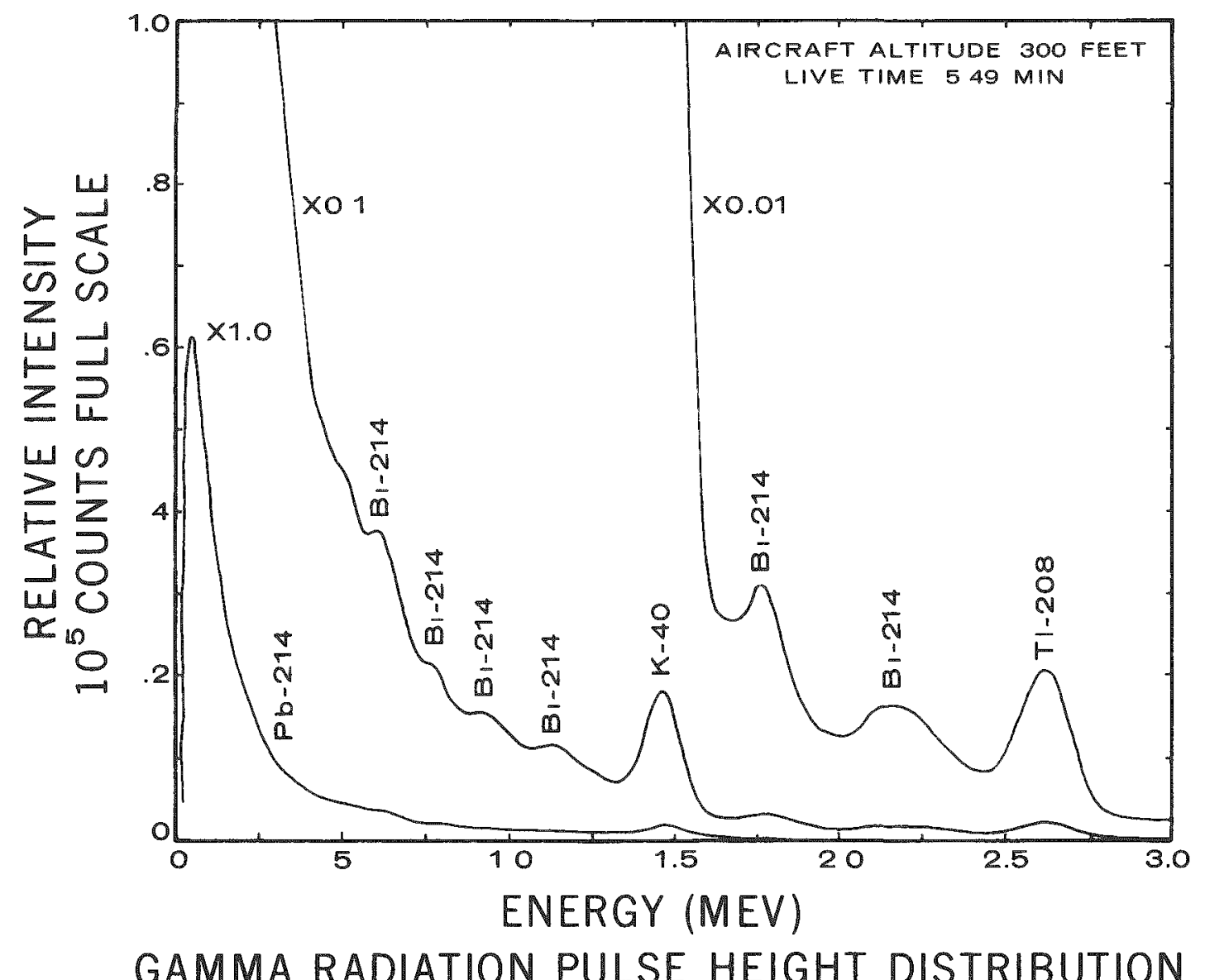

FIGURE 3. Typical spectrum for survey area. 
TABLE 3. Gamma-ray energies and isotopes consistent with spectral data of Figure 3 .

\begin{tabular}{|c|c|c|c|c|c|c|c|c|c|c|c|c|c|}
\hline \multirow{2}{*}{$\begin{array}{c}\text { Observed } \\
\text { Energy } \\
\text { (MeV) }\end{array}$} & \multicolumn{13}{|c|}{ Radionuclides Consistent with Spectral Photopeaks } \\
\hline & \multicolumn{8}{|c|}{ Fission Products } & \multicolumn{4}{|c|}{$\begin{array}{l}\text { Activation } \\
\text { Products }\end{array}$} & Background \\
\hline 0.35 & • & 。 & 。 & - & • & • & 。 & $\theta$ & • & & • & & $\mathrm{Pb}-214$ \\
\hline 0.61 & • & & • & • & • & - & 。 & & $\theta$ & & 。 & & $\mathrm{Bi}-214$ \\
\hline 0.94 & 。 & • & • & - & • & - & 。 & - & • & & 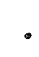 & & $\mathrm{Bi}-214$ \\
\hline 1.12 & • & & . & & • & - & 。 & - & • & & & & $\mathrm{Bi}-214$ \\
\hline 1.46 & • & & • & & • & & 。 & - & • & & 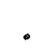 & & $\mathrm{K}-40$ \\
\hline 1.76 & . & • & 。 & 。 & • & - & 。 & • & . & & • & & $B i-214$ \\
\hline 2.20 & 。 & & • & • & - & - & 。 & • & . & 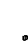 & • & & Bi -214 \\
\hline 2.62 & . & 。 & . & - & - & - & . & • & 。 & $\circ$ & • & & $\mathrm{T} 1-208$ \\
\hline
\end{tabular}

source isotopes identified in the spectrum. Differences in shape between spectra taken over different portions of the survey area are minor, and the isotopes identified in all spectra are the same. Only isotopes consistent with normal background radiation are apparent.

\section{4. $4 \quad$ Plume Track}

The the time of the survey, the rcactor was coming up to operating power after a long shutdown. A plume track was attempted, but no radiation above background levels was observed. 


\section{SUMMARY AND CONCIAUSIONS}

\section{$5.1 \quad$ Reactor Area}

The 277 square mile aerial survey of the area surrounding the Enrico Fermi Reactor revealed that both the concentration and relative abundance of radioactive isotopes are consistent with normal background radiation. No significant anomalies were detected that could be attributed to reactor operations.

The 3 -foot level exposure rates mapped during the survey werc mostly in the 6 to $15 \mathrm{uR} / \mathrm{hr}$ range.

\subsection{Plume Track}

The plume track data revealed only background radiation levels.

\section{REFERENCES}

1. "Aerial Radiological Measuring Systems (ARMS) - Systems and Procedures Employed Through FY71," AEC Report No.

ARMS-71.6, in preparation.

2. 1970 Census of Population, Advance Report PC(VI)-24, U. S. Dept. of Commerce, Bureau of Census, January 1971.

3. Burson, Z. G., Boyns, P. K., and Fritzsche, A. E., "Technical Procedures for Characterizing the Terrestrial Gamma Radiation Environment by Aerial Surveys, "EG\&G/LVAO Report No. 1183-1559, 1972. 


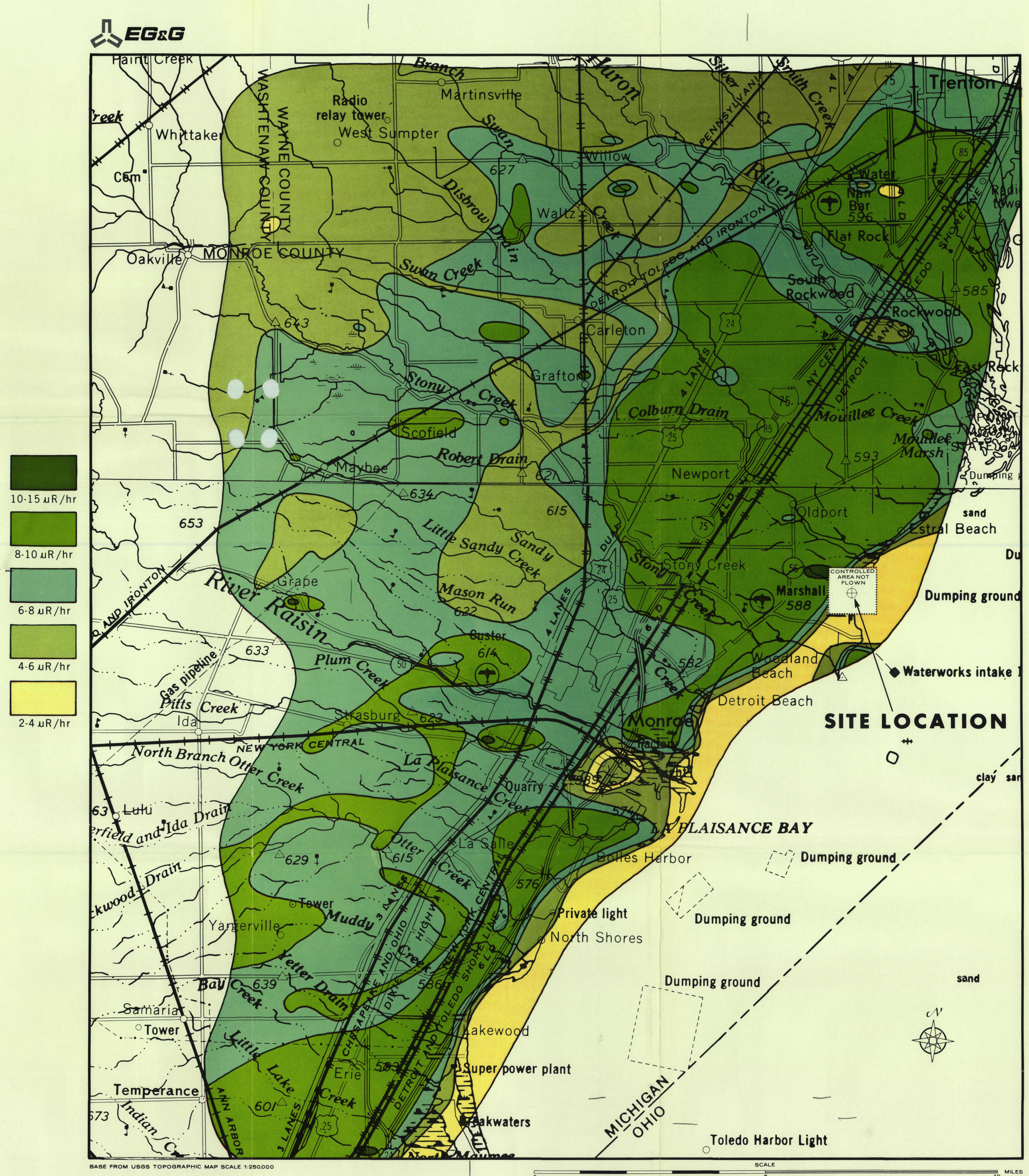

\section{GAMMA RADIATION}

CONTOUR INTERVALS SHOWN

ARE IN $\mu R / h r$ AT THE 3-FOOT LEVEL (INCLUDES TERRESTRIAL AND COSMIC RAY CONTRIBUTIONS)
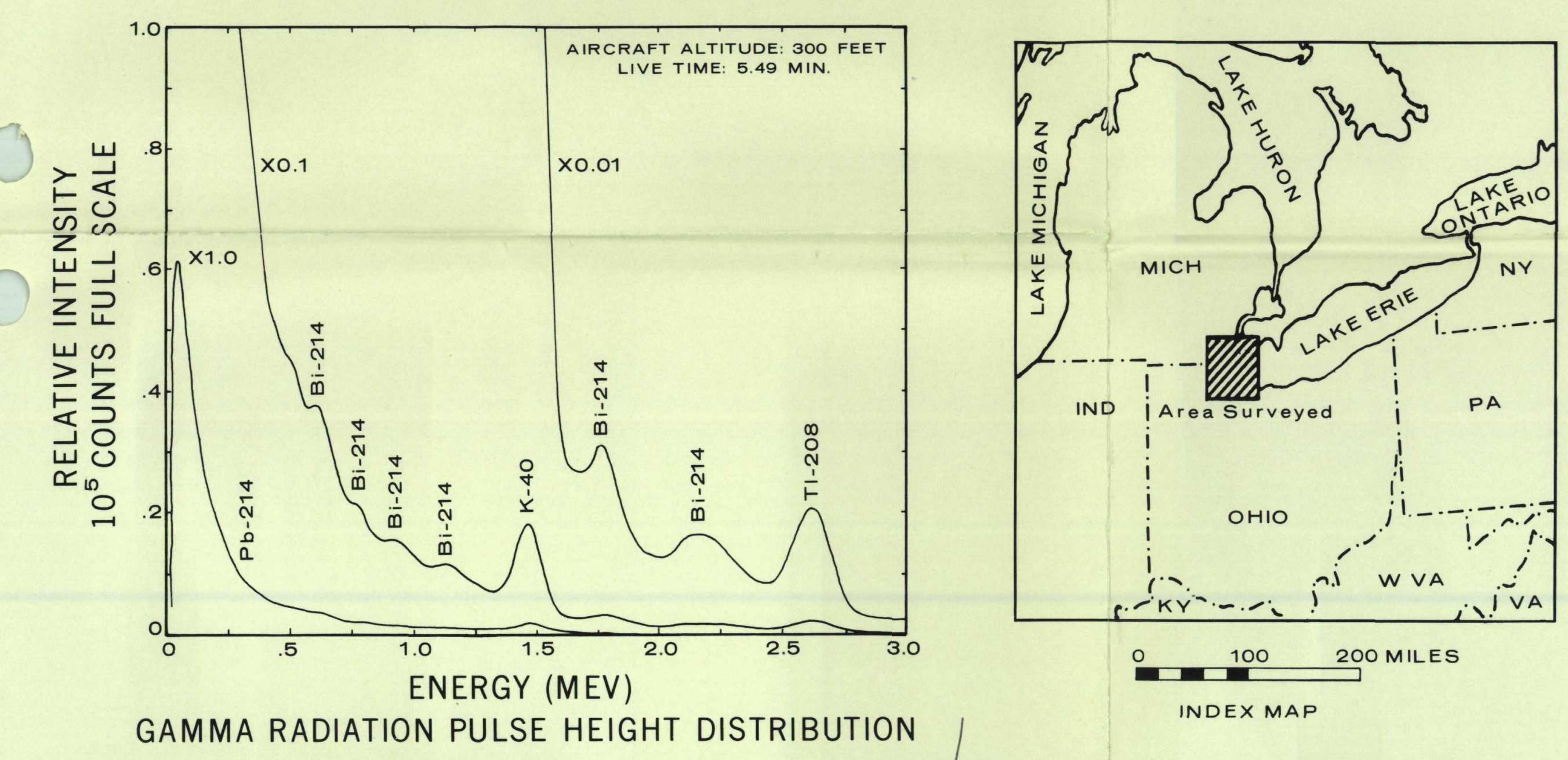

THIS SURVEY WAS MADE FOR THE USAEC WITH THE AERIAL RADIOLOGICAL MEASURING SYSTEM (ARMS).*

THE MEASUREMENTS WERE MADE USING AN ARRAY OF 144 X4 NaI SCINTILLATION DETECTORS, MOUNTED IN AN AIRCRAFT, FLOWN IN A CAREFULLY CONTROLLED PATTERN AT A 300-FOOT ALTITUDE.

DATE OF THIS SURVEY: SEPTEMBER 1970 SURVEY REPORT: ARMS 70.6.7 (ENRICO FERMI)

*(SEE REPORT: ARMS 71.6, ARMS SYSTEMS AND PROCEDURES THROUGH FY71.) 